\title{
Prevalence and outcomes of diabetes, hypertension and cardiovascular disease in COPD
}

\author{
D.M. Mannino*, D. Thorn", A. Swensen ${ }^{\#}$ and F. Holguin
}

ABSTRACT: Chronic obstructive pulmonary disease (COPD) is associated with important chronic comorbid diseases, including cardiovascular disease, diabetes and hypertension.

The present study analysed data from 20,296 subjects aged $\geqslant 45$ yrs at baseline in the Atherosclerosis Risk in Communities Study (ARIC) and the Cardiovascular Health Study (CHS). The sample was stratified based on baseline lung function data, according to modified Global Initiative for Obstructive Lung Disease (GOLD) criteria. Comorbid disease at baseline and death and hospitalisations over a 5-yr follow-up were then searched for.

Lung function impairment was found to be associated with more comorbid disease. In logistic regression models adjusting for age, sex, race, smoking, body mass index and education, subjects with GOLD stage 3 or 4 COPD had a higher prevalence of diabetes (odds ratio (OR) 1.5, 95\% confidence interval $(\mathrm{Cl})$ 1.1-1.9), hypertension (OR 1.6, 95\% $\mathrm{Cl} 1.3-1.9)$ and cardiovascular disease (OR 2.4, 95\% Cl 1.9-3.0). Comorbid disease was associated with a higher risk of hospitalisation and mortality that was worse in people with impaired lung function.

Lung function impairment is associated with a higher risk of comorbid disease, which contributes to a higher risk of adverse outcomes of mortality and hospitalisations.

KEYWORDS: Cardiovascular, diabetes, hypertension, lung function, mortality

hronic obstructive pulmonary disease (COPD) is an important cause of morbidity and mortality in the USA and around the world [1, 2]. In recent years the approach towards patients with COPD has moved away from nihilism and towards viewing this disease as both preventable and treatable [3].

An important factor in both the prognosis and functional capabilities of COPD patients is the role of comorbid disease $[4,5]$. There are several important steps in evaluating comorbid disease in COPD. The first is to define the diseases that occur with an increasing frequency in subjects with evidence of COPD, and the second is to determine the effect that comorbid disease has on health-related outcomes. The disease processes most closely linked to COPD include lung cancer [6], depression [7], congestive heart failure [5] and ischaemic heart disease [5]. However, there are several other diseases potentially linked to respiratory disease or its treatment with a weaker association, i.e. osteoporosis [8], cataracts [9], hypertension [10] and diabetes mellitus [11].

The aim of the present study was to determine the relationship between COPD and the common, chronic comorbid conditions of cardiovascular disease, hypertension and diabetes mellitus, and to determine how these affect the outcomes of hospitalisations and death. This analysis was carried out by combining two existing databases, the Atherosclerosis Risk in Communities Study (ARIC) [12] and the Cardiovascular Health Study (CHS) [13], which are described below.

\section{MATERIALS AND METHODS}

Data from the CHS and ARIC cohorts were combined, both of which were population-based National Institute of Health cohorts initiated in the late 1980s. These cohorts were designed to study subjects of different ages ( $\geqslant 65$ yrs for CHS and 45-64 yrs for ARIC) with comprehensive evaluations, including lung function and longitudinal follow-up. ARIC and CHS data that is publicly available from the National Heart, Lung and Blood Institute was analysed.

\section{CHS study population}

The original CHS cohort of 5,201 males and females was selected using Medicare eligibility lists provided by the US Health Care Financing Administration for four communities, Forsyth

\section{AFFILIATIONS}

*Dept of Preventive Medicine and Environmental Health, University of Kentucky College of Public Health, Lexington, $K Y$,

${ }^{\#}$ Novartis Pharmaceuticals

Corporation, East Hanover, NJ, and

'Emory University College of

Medicine, Atlanta, GA, USA.

CORRESPONDENCE

D.M. Mannino

Dept of Preventive Medicine and Environmental Health

University of Kentucky College of

Public Health

121 Washington Avenue

Lexington

KY 40536

USA

Fax: 18592571044

E-mail: dmannino@uky.edu

Received:

January 252008

Accepted after revision:

June 052008

\section{STATEMENT OF INTEREST}

Statements of interest for D. Thorn, A. Swensen, and for the study itself can be found at www.erj.ersjournals. com/misc/statements.shtml

European Respiratory Journal Print ISSN 0903-1936 Online ISSN 1399-3003 
County (NC), Pittsburgh (PA), Sacramento County (CA) and Washington County (MA), during the period of May 1989 to May 1990 [13]. CHS subjects underwent pulmonary function testing during a baseline clinical examination and provided information on history of respiratory symptoms and diagnoses, body mass index (BMI), smoking history and medical history. Study protocols were approved for the protection of human subjects. Details of the CHS have been published elsewhere [13]. The present analysis was limited to CHS subjects who provided baseline information on respiratory symptoms, underwent pulmonary function testing at the baseline examination, and for whom follow-up data were available.

\section{ARIC study population}

The original ARIC cohort, initiated in 1986, included 15,792 adults aged 45-64 yrs and was a population-based study of the aetiology and clinical sequelae of atherosclerosis. Study protocols were approved for the protection of human subjects. Details of the ARIC study have been published elsewhere [12]. The current analysis was limited to ARIC subjects who provided baseline information on respiratory symptoms, who underwent pulmonary function testing at the baseline examination, and for whom follow-up data were available.

\section{Pulmonary function data}

Spirometry was conducted using a volume displacement, water-sealed spirometer. At least three acceptable spirograms were obtained from a minimum of five forced expirations. The best single spirogram was identified by computer and confirmed by a technician. Quality assurance was provided by the CHS Pulmonary Function Center (Tuscon, AZ, USA) and the ARIC coordinating center (Chapel Hill, NC, USA) for the CHS and ARIC cohorts, respectively. All procedures followed the American Thoracic Society guidelines [14]. Several measures of lung function were used: forced expiratory volume in one second (FEV1), forced vital capacity (FVC), and FEV1/FVC ratio. The prediction equations developed by HANKINSON et al. [15] were used to determine predicted levels of lung function.

\section{Variable definition}

Age, sex, race and highest education level obtained were selfreported. Age was stratified into 4-5-yr categories, race was classified as white or black, and education level was classified as $<12$ yrs, 12 yrs or $>12$ yrs. Responses to the questions "Have you ever smoked cigarettes?" and "Do you now smoke cigarettes?" were used to classify subjects as current, former and never-smokers. BMI was calculated as weight divided by height squared $\left(\mathrm{kg} \cdot \mathrm{m}^{-2}\right)$ [16].

Using a modification of the criteria developed by the Global Initiative for Chronic Obstructive Lung Disease (GOLD) [17, 18], subjects were classified at baseline according to their GOLD COPD stage as follows. GOLD stage 3 or 4 : FEV1/FVC $<0.70$ and FEV1 $<50 \%$ predicted; GOLD stage 2: FEV1/FVC $<0.70$ and FEV1 $\geqslant 50$ to $<80 \%$ pred; GOLD stage 1 : FEV1/FVC $<0.70$ and $\mathrm{FEV} 1 \geqslant 80 \%$; restricted: FEV1/FVC $\geqslant 0.70$ and FVC $<80 \%$ pred; GOLD stage 0: presence of respiratory symptoms in the absence of any lung function abnormality; and no lung disease. A subject was defined as having a respiratory symptom (used to classify
GOLD stage 0 lung function status) if they responded positively to any of the following questions: "Do you usually have a cough?"; "Do you usually bring up phlegm from your chest?"; "Does your chest ever sound wheezy or whistling apart from colds?"; "Do you have to walk slower than people of your age on the level because of breathlessness?"; and "Are you too breathless to leave the house or breathless on dressing or undressing?". GOLD stage 0 does not appear in the most recent guideline revisions but it is included in the analysis as the present authors have previously demonstrated adverse outcomes among people in this category $[18,19]$. Bronchodilator response was not evaluated in this survey so classification is based on the pre-bronchodilator level. Some subjects may have taken a bronchodilator prior to spirometry, but data on this were not available.

Subjects were classified as having diabetes if they reported either a diagnosis of diabetes at baseline or had impaired fasting or post-glucose load glucose levels $\left(>140 \mathrm{mg} \cdot \mathrm{dL}^{-1}\right)$ upon examination. Subjects reporting a diagnosis of a previous myocardial infarction, stroke, heart failure, angina or transient ischaemic attacks were classified as having cardiovascular disease at the baseline examination. Subjects were classified as having hypertension if they reported physician diagnosis of hypertension, were receiving treatment for hypertension or had evidence of hypertension upon examination (diastolic blood pressure $\geqslant 90 \mathrm{mmHg}$ or a systolic blood pressure $\geqslant 140 \mathrm{mmHg}$, based on three measurements). In addition, the present authors summed the three comorbid conditions (cardiovascular disease, hypertension and diabetes) and classified each subject as having none, one, two or three diseases. Only comorbid disease at baseline was included in the analysis. Analyses were limited to subjects in whom complete data on demographic factors, risk factors and baseline comorbid disease were available.

\section{Hospitalisations and deaths}

Hospitalisation data were searched and events were defined as any hospitalisations that occurred during 5 yrs of follow-up after the baseline evaluation. The time interval from study entry to the initial hospitalisation was determined for each subject. In deceased subjects, follow-up was counted from the date of the baseline survey to either the date of death or for 5 yrs.

\section{Statistical analysis}

The main outcomes were the prevalence of diabetes mellitus, hypertension and cardiovascular disease or combinations of these diseases at the baseline evaluation. The relationship between respiratory impairment, comorbid disease and mortality, and hospitalisations was also determined using Cox proportional hazard models.

Logistic and multinomial logistic regression models were developed, using the SUDAAN (Research Triangle International, Research Triangle Park, NC, USA) procedures RLOGIST and MULTILOG, to determine the association between the categories of respiratory impairment and diabetes mellitus, hypertension and cardiovascular disease (RLOGIST) or combinations of disease (MULTILOG). These models were adjusted for age, sex, race, smoking status, education level and BMI. 


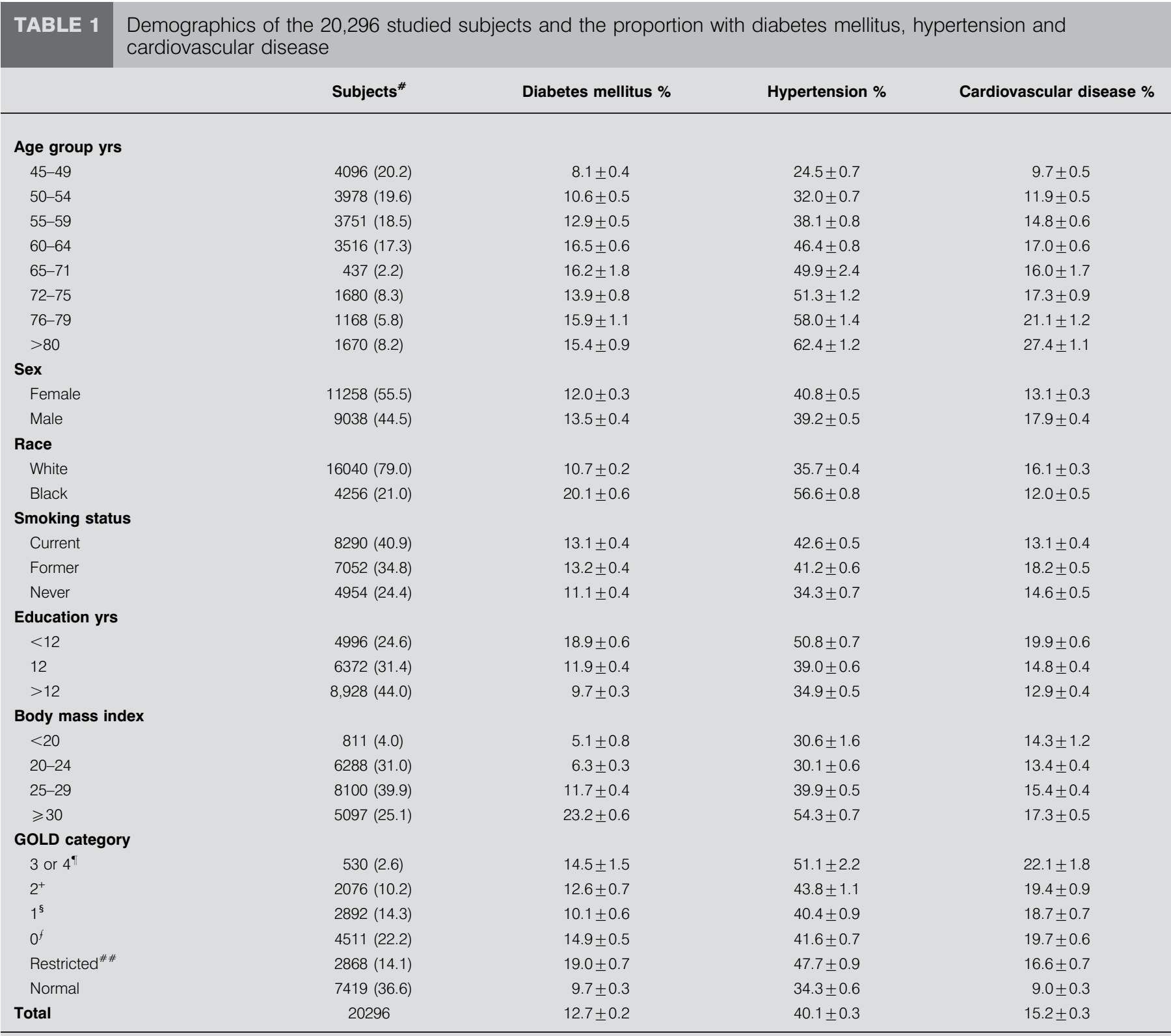

Data are presented as $n(\%)$ or mean \pm SEM. GOLD: Global Initiative for Obstructive Lung Disease. ${ }^{\#}$ : subjects in the Atherosclerosis Risk in Communities Study during 1986-1989 and the Cardiovascular Health Study during 1989-1990; $"$ : forced expiratory volume in one second (FEV1) or forced vital capacity (FVC) <0.70 and FEV 1 $<50 \%$ predicted; ${ }^{+}: \mathrm{FEV}_{1} / \mathrm{FVC}<0.70$ and $\mathrm{FEV}_{1} \geqslant 50$ to $<80 \%$ pred; ${ }^{\text {s. }} \mathrm{FEV} 1 / \mathrm{FVC}<0.70$ and $\mathrm{FEV}_{1} \geqslant 80 \%$ pred; $f^{f}$ : presence of respiratory symptoms in the absence of any lung function abnormality; ${ }^{\# \#}$ : FEV1/FVC $\geqslant 0.70$ and $\mathrm{FVC}<80 \%$ pred.

Cox-proportional hazard regression models for death and hospitalisation were developed, using the SUDAAN procedure SURVIVAL, to account for differential follow-up in cohort subjects. Time of follow-up was used as the underlying time metric. Censoring occurred at the date of death reported on the death certificate or the date the subject was last known to be alive. For the hospitalisation models, the current authors censored at the date of first hospitalisation, date of death reported on the death certificate, or date the participant was last known to be alive. Plots of the log-log survival curves for each covariate were produced to evaluate the proportional hazards assumptions. These models were used to determine the association between the categories of respiratory impairment, comorbid disease and death or hospitalisations. Age, sex, race, smoking status, education level and BMI were included in the adjusted models. Models were evaluated for interaction between the class of lung function impairment, comorbid disease and the outcomes of death or time to first hospitalisation.

\section{RESULTS}

The final cohort consisted of 15,341 (97.1\%) out of 15,792 subjects from the ARIC cohort and 4,955 (95.3\%) out of 5,201 CHS subjects. The demographics of the studied population are shown in table 1 . 
Overall, GOLD stage 3 or 4 COPD was present in $530(2.6 \%)$ subjects, GOLD Stage 2 COPD in 2,076 (10.2\%) and restriction on spirometry was present in 2,868 (14.1\%) subjects. Diabetes, hypertension and cardiovascular disease were present in 2,570 $(12.7 \%), 8,137(40.1 \%)$ and 3,091 (15.2\%) subjects, respectively (table 1).

Analyses showed that increasing age, a higher BMI, lower education status and male sex were associated with a higher risk of diabetes, hypertension and cardiovascular disease (table 1). In multivariate analyses, GOLD stage 3 or 4 COPD was associated with a higher risk of diabetes (odds ratio (OR) $1.5,95 \%$ confidence interval (CI) 1.1-1.9), hypertension (OR 1.6, 95\% CI 1.3-1.9) and cardiovascular disease (OR 2.4, 95\% CI 1.9-3.0). Similar findings were seen for GOLD stage 2 COPD, GOLD stage 0 COPD and restricted subjects (table 2).

In the present study cohort, 9,925 (48.9\%) subjects had no comorbid disease, $7,359(36.3 \%)$ had one comorbid disease, $2,597(12.8 \%)$ had two comorbid diseases and $415(2.0 \%)$ had three comorbid diseases (table 3). Multinomial logistic regression showed that compared to subjects with normal lung function, those with GOLD stage 3 or 4 COPD were more likely to have one (OR 1.8, 95\% CI 1.5-2.3), two (OR 2.9, 95\% CI 2.23.8 ) or three (OR 3.5, 95\% CI 1.9-6.4) comorbid diseases, with similar effects seen among restricted subjects and those with GOLD stage 2 COPD and GOLD stage 0 COPD (table 4).

Within 5 yrs of baseline evaluation, 1,202 (5.9\%) study subjects died. The presence of respiratory impairment and comorbid disease predicted higher mortality, with cardiovascular disease and diabetes mellitus demonstrating a larger effect on mortality than hypertension (fig. 1). The combination of multiple comorbid diseases, along with respiratory impairment, also resulted in a higher risk of death (fig. 2). For example, a subject with GOLD

\section{TABLE 2 Multivariate regression predicting diabetes mellitus, hypertension and cardiovascular disease}

\begin{tabular}{lccc} 
& $\begin{array}{c}\text { Diabetes } \\
\text { mellitus }\end{array}$ & Hypertension & $\begin{array}{c}\text { Cardiovascular } \\
\text { disease }\end{array}$ \\
\hline $\begin{array}{l}\text { GOLD category } \\
\quad 3 \text { or } 4^{\#}\end{array}$ & & & \\
$2^{\boldsymbol{*}}$ & $1.5(1.1-1.9)$ & $1.6(1.3-1.9)$ & $2.4(1.9-3.0)$ \\
$1^{+}$ & $1.4(1.2-1.6)$ & $1.4(1.3-1.6)$ & $2.2(1.9-2.5)$ \\
$0^{\text {s }}$ & $0.9(0.8-1.1)$ & $1.1(0.9-1.2)$ & $1.7(1.5-1.9)$ \\
Restricted $^{f}$ & $1.4(1.3-1.6)$ & $1.2(1.1-1.3)$ & $2.4(2.1-2.8)$ \\
Normal & $2.1(1.9-2.5)$ & $1.5(1.4-1.7)$ & $2.4(2.1-2.7)$ \\
\hline
\end{tabular}

Data are presented as odds ratio (95\% confidence interval). Models were adjusted for age, sex, race, smoking status, education level and body mass index from 20,296 study subjects from the Atherosclerosis Risk in Communities Study during 1986-1989 and the Cardiovascular Health Study during 1989-1990.

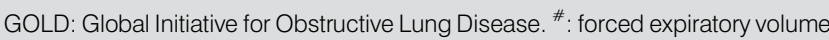
in one second (FEV 1 )/forced vital capacity (FVC) $<0.70$ and $\mathrm{FEV}_{1}<50 \%$ predicted; " ${ }^{\circ}$ FEV $1 / F V C<0.70$ and FEV $1 \geqslant 50$ to $<80 \%$ pred; ${ }^{+}$: FEV $1 / F V C<0.70$ and $\mathrm{FEV}_{1} \geqslant 80 \%$ pred; ${ }^{\mathrm{s}}$ : presence of respiratory symptoms in the absence of any lung function abnormality; ${ }^{f}$ : $\mathrm{FEV} 1 / \mathrm{FVC} \geqslant 0.70$ and $\mathrm{FVC}<80 \%$ pred.

\begin{tabular}{|c|c|c|c|c|c|}
\hline \multirow[t]{3}{*}{ TABLE 3} & \multicolumn{5}{|c|}{$\begin{array}{l}\text { Demographics of the } 20,296 \text { studied subjects } \\
\text { and the proportion with comorbid diseases } \\
\text { at baseline }\end{array}$} \\
\hline & \multirow[t]{2}{*}{ Subjects ${ }^{\#}$} & \multicolumn{4}{|c|}{ Comorbid disease \% } \\
\hline & & 0 & 1 & 2 & 3 \\
\hline \multicolumn{6}{|l|}{ Age group yrs } \\
\hline $45-49$ & 4096 (20.2) & $65.2 \pm 0.7$ & $27.9 \pm 0.7$ & $6.2 \pm 0.4$ & $0.7 \pm 0.1$ \\
\hline $50-54$ & 3978 (19.6) & $57.4 \pm 0.8$ & $31.9 \pm 0.7$ & $9.5 \pm 0.5$ & $1.3 \pm 0.2$ \\
\hline $55-59$ & 3751 (18.5) & $50.2 \pm 0.8$ & $35.6 \pm 0.8$ & $12.5 \pm 0.5$ & $1.8 \pm 0.2$ \\
\hline $60-64$ & 3516 (17.3) & $41.6 \pm 0.8$ & $39.6 \pm 0.8$ & $15.9 \pm 0.6$ & $2.8 \pm 0.3$ \\
\hline $65-71$ & $437(2.2)$ & $41.2 \pm 2.4$ & $38.2 \pm 2.3$ & $17.8 \pm 1.8$ & $2.7 \pm 0.8$ \\
\hline $72-75$ & $1680(8.3)$ & $39.6 \pm 1.2$ & $42.1 \pm 1.2$ & $14.6 \pm 0.9$ & $3.8 \pm 0.5$ \\
\hline $76-79$ & $1168(5.8)$ & $31.1 \pm 1.4$ & $46.4 \pm 1.5$ & $18.8 \pm 1.1$ & $3.7 \pm 0.6$ \\
\hline$\geqslant 80$ & $1670(8.2)$ & $24.9 \pm 1.1$ & $48.1 \pm 1.2$ & $23.8 \pm 1.0$ & $3.2 \pm 0.4$ \\
\hline \multicolumn{6}{|l|}{ Sex } \\
\hline Female & $11258(55.5)$ & $49.9 \pm 0.5$ & $35.9 \pm 0.5$ & $12.6 \pm 0.3$ & $1.6 \pm 0.1$ \\
\hline Male & $9038(44.5)$ & $47.7 \pm 0.5$ & $36.7 \pm 0.5$ & $13.1 \pm 0.4$ & $2.5 \pm 0.2$ \\
\hline \multicolumn{6}{|l|}{ Race } \\
\hline White & $16040(79.0)$ & $52.7 \pm 0.4$ & $33.9 \pm 0.4$ & $11.5 \pm 0.3$ & $1.9 \pm 0.1$ \\
\hline Black & $4256(21.0)$ & $34.5 \pm 0.7$ & $45.2 \pm 0.8$ & $17.6 \pm 0.6$ & $2.8 \pm 0.3$ \\
\hline \multicolumn{6}{|l|}{ Smoking status } \\
\hline Current & $8290(40.9)$ & $53.7 \pm 0.7$ & $34.0 \pm 0.7$ & $11.0 \pm 0.4$ & $1.4 \pm 0.2$ \\
\hline Former & 7052 (34.8) & $46.5 \pm 0.6$ & $37.2 \pm 0.6$ & $13.6 \pm 0.4$ & $2.7 \pm 0.2$ \\
\hline Never & $4954(24.4)$ & $48.1 \pm 0.5$ & $36.9 \pm 0.5$ & $13.2 \pm 0.4$ & $1.9 \pm 0.1$ \\
\hline \multicolumn{6}{|l|}{ Education yrs } \\
\hline$<12$ & 4996 (24.6) & $35.8 \pm 0.7$ & $41.9 \pm 0.7$ & $19.0 \pm 0.6$ & $3.2 \pm 0.2$ \\
\hline 12 & $6372(31.4)$ & $49.7 \pm 0.6$ & $36.5 \pm 0.6$ & $12.0 \pm 0.4$ & $1.8 \pm 0.2$ \\
\hline$>12$ & $8928(44.0)$ & $55.6 \pm 0.5$ & $32.9 \pm 0.5$ & $9.9 \pm 0.3$ & $1.6 \pm 0.1$ \\
\hline \multicolumn{6}{|l|}{ BMI } \\
\hline$<20$ & $811(4.0)$ & $58.6 \pm 1.7$ & $33.4 \pm 1.7$ & $7.5 \pm 0.9$ & $0.5 \pm 0.2$ \\
\hline $20-24$ & $6288(31.0)$ & $60.4 \pm 0.6$ & $30.5 \pm 0.6$ & $8.2 \pm 0.3$ & $1.0 \pm 0.1$ \\
\hline $25-29$ & 8100 (39.9) & $48.6 \pm 0.6$ & $37.6 \pm 0.5$ & $12.0 \pm 0.4$ & $1.8 \pm 0.1$ \\
\hline$\geqslant 30$ & 5097 (25.1) & $33.7 \pm 0.7$ & $41.7 \pm 0.7$ & $20.6 \pm 0.6$ & $4.0 \pm 0.3$ \\
\hline \multicolumn{6}{|l|}{ GOLD category } \\
\hline 3 or $4^{\circ}$ & $530(2.6)$ & $35.1 \pm 2.1$ & $44.7 \pm 2.2$ & $17.5 \pm 1.7$ & $2.6 \pm 0.7$ \\
\hline $2^{+}$ & 2076 (10.2) & $44.5 \pm 1.1$ & $37.6 \pm 1.1$ & $15.6 \pm 0.8$ & $2.4 \pm 0.3$ \\
\hline $1^{\S}$ & 2892 (14.3) & $47.3 \pm 0.9$ & $37.7 \pm 0.9$ & $13.6 \pm 0.6$ & $1.4 \pm 0.2$ \\
\hline $0^{f}$ & $4511(22.2)$ & $45.5 \pm 0.7$ & $36.1 \pm 0.7$ & $15.3 \pm 0.5$ & $3.2 \pm 0.3$ \\
\hline Restricted ${ }^{\# \#}$ & $2868(14.1)$ & $40.8 \pm 0.9$ & $38.4 \pm 0.9$ & $17.7 \pm 0.7$ & $3.2 \pm 0.3$ \\
\hline Normal & 7419 (36.6) & $57.0 \pm 0.6$ & $34.0 \pm 0.6$ & $8.0 \pm 0.3$ & $1.0 \pm 0.1$ \\
\hline Total & 20296 & $48.9 \pm 0.4$ & $35.3 \pm 0.3$ & $12.8 \pm 0.2$ & $2.0 \pm 0.1$ \\
\hline
\end{tabular}

Data are presented as $n(\%)$ or mean \pm SEM. BMI: body mass index; GOLD: Global Initiative for Obstructive Lung Disease. ${ }^{*}$ : subjects in the Atherosclerosis Risk in Communities Study during 1986-1989 and the Cardiovascular Health Study during 1989-1990; ": forced expiratory volume in one second (FEV1)/ forced vital capacity (FVC) $<0.70$ and $\mathrm{FEV}_{1}<50 \%$ predicted; ${ }^{+}$: FEV $1 / \mathrm{FVC}$ $<0.70$ and $\mathrm{FEV}_{1} \geqslant 50$ to $<80 \%$ pred; ${ }^{\text {s. }}$ FEV $1 / \mathrm{FVC}<0.70$ and $\mathrm{FEV}_{1} \geqslant 80 \%$ pred; ${ }^{f}$ : presence of respiratory symptoms in the absence of any lung function abnormality; ${ }^{\# \#: ~ F E V 1 / F V C ~} \geqslant 0.70$ and FVC $<80 \%$ pred.

stage 3 or 4 COPD and all three comorbid diseases had a 20-fold higher risk of death than a subject with normal lung function and no comorbid disease (fig. 2). There was no significant interaction between respiratory impairment, comorbid disease and death ( $\mathrm{p}>0.10$ for all models). 


\begin{tabular}{|c|c|c|c|}
\hline \multirow[t]{3}{*}{ TABLE 4} & \multicolumn{3}{|c|}{$\begin{array}{l}\text { Multinomial logistic regression predicting the } \\
\text { presence of comorbid diseases }\end{array}$} \\
\hline & \multicolumn{3}{|c|}{ Comorbid disease } \\
\hline & 1 & 2 & 3 \\
\hline \multicolumn{4}{|c|}{ GOLD category } \\
\hline 3 or $4^{\#}$ & $1.8(1.5-2.3)$ & $2.9(2.2-3.8)$ & $3.5(1.9-6.4)$ \\
\hline $2^{*}$ & $1.4(1.3-1.6)$ & $2.4(2.0-2.9)$ & $3.2(2.2-4.6)$ \\
\hline $1^{+}$ & $1.1(0.96-1.2)$ & $1.4(1.2-1.7)$ & $1.0(0.7-1.5)$ \\
\hline $0^{\S}$ & $1.3(1.2-1.4)$ & $2.1(1.9-2.4)$ & $3.6(2.7-4.9)$ \\
\hline Restricted $f$ & $1.5(1.4-1.7)$ & $3.0(2.6-3.5)$ & $6.1(4.3-8.7)$ \\
\hline Normal & 1.0 & 1.0 & 1.0 \\
\hline \multicolumn{4}{|c|}{ 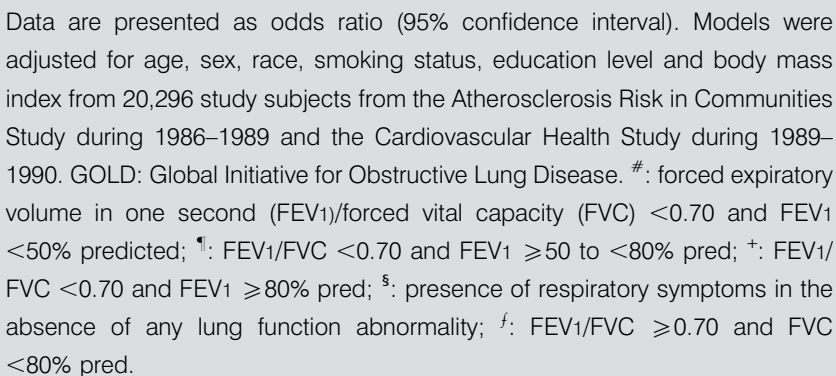 } \\
\hline
\end{tabular}

At least one hospitalisation during the first 5 yrs of follow-up occurred in $4,537(22.4 \%)$ study subjects. The risk of any hospitalisation was increased among study subjects with respiratory impairment and comorbid disease, either alone or in combination (figs 3 and 4). There was a significant interaction between respiratory impairment, comorbid disease and hospitalisation ( $\mathrm{p}<0.05$ for all models).

\section{DISCUSSION}

In the current analysis, the presence of respiratory impairment, as determined using both lung function measurement and the presence of respiratory symptoms, was associated with a higher risk of having comorbid hypertension, cardiovascular disease and diabetes, and of also having at least two of these comorbid diseases. In addition, the presence of these comorbid diseases further modified the effect that respiratory impairment had on the outcomes of all-cause mortality and hospitalisation during $5 \mathrm{yrs}$ of follow-up. While a significant interaction was found between respiratory impairment, comorbid disease and hospitalisations, but not deaths, this may have been related to the far larger number of hospitalisations $(4,537$ versus 1,202$)$.

The association between respiratory disease and cardiovascular disease is an area of research that has received a great deal of attention in recent years [20-22]. The reasons for this association are unclear, but may be related to systemic inflammation, chronic infections, shared risk factors (such as smoking) or other undefined factors [23-25]. A recent analysis of the ARIC data demonstrates that respiratory impairment predicts the development or recurrence of cardiovascular disease [26]. This relationship, however, is decreased after adjusting for fibrinogen, a marker of systemic inflammation, which suggests that the relationship between COPD and
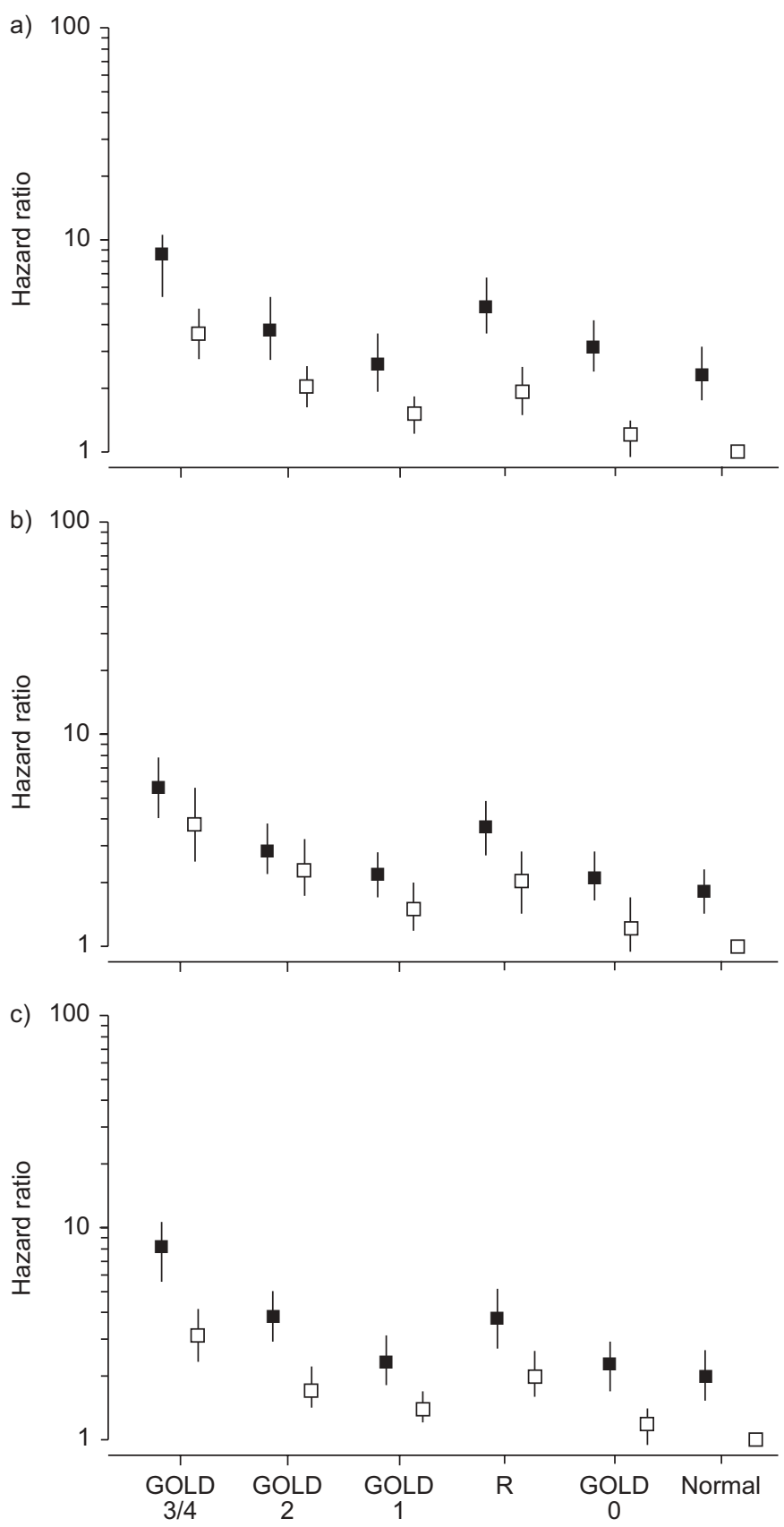

FIGURE 1. Results from Cox proportional hazard models (presented as hazard ratio with 95\% confidence interval) that predict death within $5 \mathrm{yrs}$ by modified Global Initiative for Obstructive Lung Disease (GOLD) category and the presence of a) diabetes, b) hypertension or c) cardiovascular disease. The reference group (normal) was subjects with normal lung function who do not have the comorbid disease of interest. Models were adjusted for age, sex, race, smoking status, education level and body mass index. Subjects were from the Atherosclerosis Risk in Communities Study during 1986-1989 and the Cardiovascular Health Study during 1989-1990. $\mathbf{\square}$ : with comorbid disease; $\square$ : without comorbid disease. GOLD 3/4: forced expiratory volume in one second (FEV1)/forced vital capacity $(F V C)<0.70$ and $F E V_{1}<50 \%$ predicted; GOLD 2: $\mathrm{FEV}_{1} / \mathrm{FVC}<0.70$ and $\mathrm{FEV}_{1} \geqslant 50$ to $<80 \%$ pred; GOLD 1: FEV $1 / F V C<0.70$ and $\mathrm{FEV}_{1} \geqslant 80 \%$ pred; restricted (R): FEV $1 / F V C \geqslant 0.70$ and $\mathrm{FVC}<80 \%$ pred; GOLD 0 : presence of respiratory symptoms in the absence of any lung function abnormality and no lung disease. 


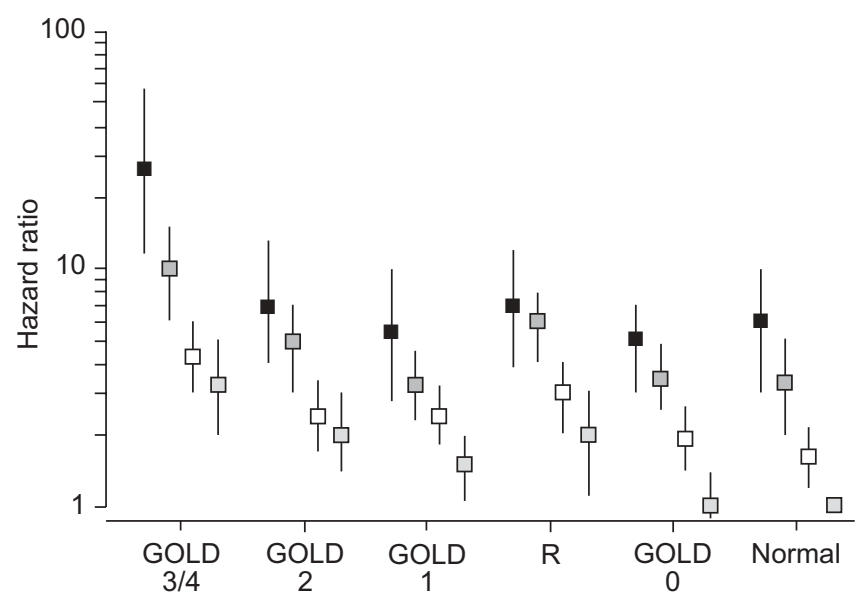

FIGURE 2. Results from Cox proportional hazard models (presented as hazard ratio with $95 \%$ confidence interval) that predict death within 5 yrs by modified Global Initiative for Obstructive Lung Disease (GOLD) category and the presence of no $(\square)$, one $(\square)$, two $(\square)$ or three $(\square)$ comorbid diseases (diabetes, hypertension or cardiovascular disease). The reference group (normal) was subjects with normal lung function for each comorbid disease. Models were adjusted for age, sex, race, smoking status, education level and body mass index. Subjects were from the Atherosclerosis Risk in Communities Study during 19861989 and the Cardiovascular Health Study during 1989-1990. GOLD 3/4: forced expiratory volume in one second (FEV1)/forced vital capacity (FVC) $<0.70$ and FEV1 $<50 \%$ predicted; GOLD 2: FEV $1 / F V C<0.70$ and $F E V_{1} \geqslant 50$ to $<80 \%$ pred; GOLD 1: $\mathrm{FEV}_{1} / \mathrm{FVC}<0.70$ and $\mathrm{FEV}_{1} \geqslant 80 \%$ pred; restricted $(\mathrm{R})$ : $\mathrm{FEV}_{1} / \mathrm{FVC} \geqslant 0.70$ and $\mathrm{FVC}<80 \%$ pred; GOLD 0: presence of respiratory symptoms in the absence of any lung function abnormality and no lung disease.

cardiovascular disease may be, in part, related to other factors [26]. In addition, there is evidence that smoking can also increase susceptibility to infection [27] and can increase levels of inflammatory markers in the serum [28].

An interesting finding in the current analysis was that subjects with normal lung function but respiratory symptoms (formerly known as GOLD stage 0 ) had a risk of cardiovascular disease as high as people with GOLD stage 3 or 4 COPD (table 2). The presence of respiratory symptoms in the absence of lung function impairment is found in a significant proportion of patients [29]. Many of these patients probably have cough or wheeze associated with asthma, gastro-oesophageal reflux or sinusitis [30]. In some cases, this may be an early manifestation of COPD [31]. In others, as the present analysis suggests, this may be an indication of comorbid cardiovascular disease. Thus, the presence of respiratory symptoms, whether or not lung function is abnormal, is important both epidemiologically and clinically.

Similarly, the presence of restriction on spirometry has been found to be associated with diabetes [32-34] and predictive of the development of diabetes [11, 32]. A novel finding in the analysis was a modest association of subjects with GOLD stage 2 COPD or higher and those with GOLD stage 0 COPD with diabetes (table 2). This relationship is interesting and merits further investigation, with the potential to reveal new information on the development of both COPD and diabetes. Potential mechanisms explaining the relationship between respiratory impairment and diabetes might be an increased
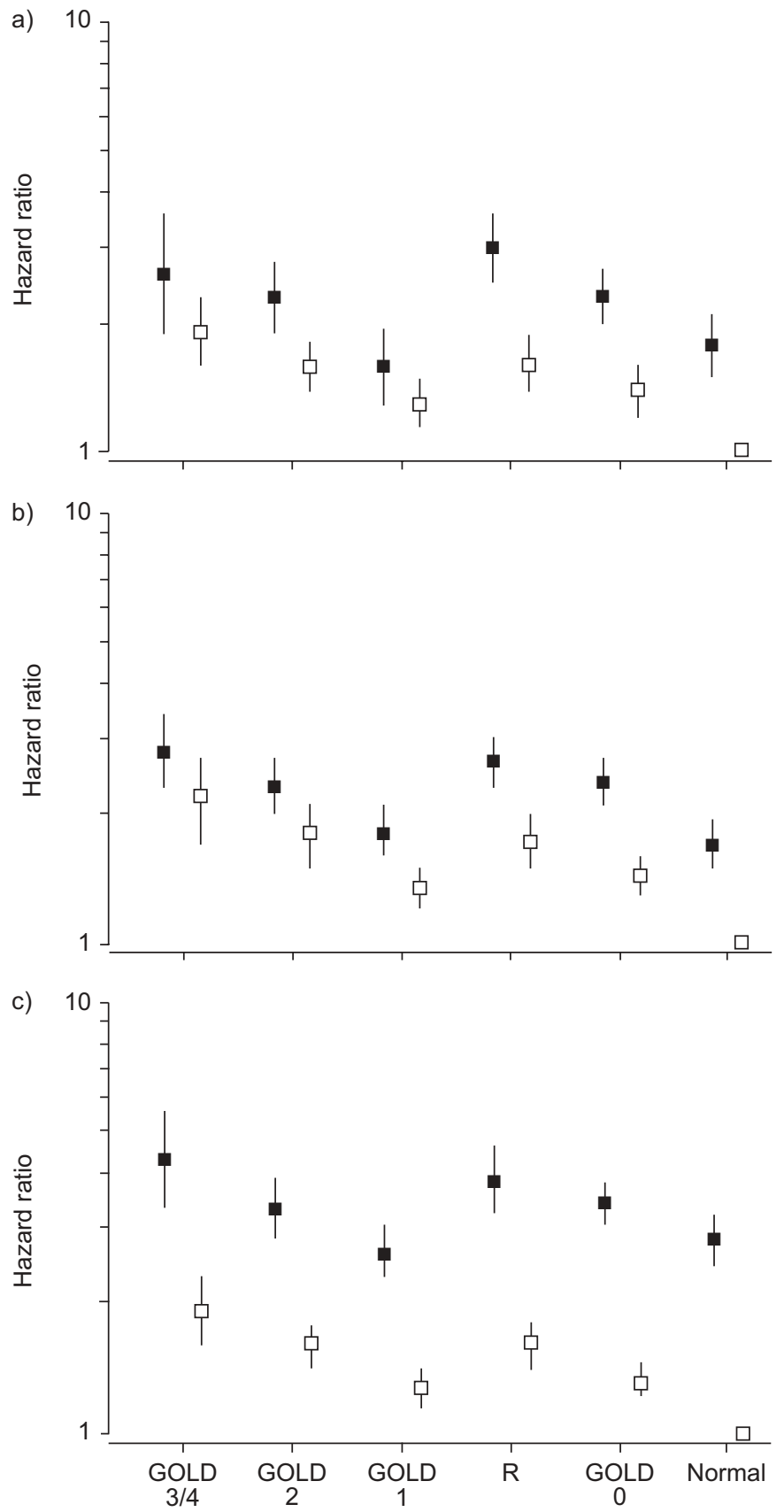

FIGURE 3. Results from Cox proportional hazard models (presented as hazard ratio with $95 \%$ confidence interval) that predict time to first hospitalisation within 5 yrs by modified Global Initiative for Obstructive Lung Disease (GOLD) category and the presence of a) diabetes, b) hypertension or c) cardiovascular disease. The reference group (normal) comprised subjects with normal lung function who do not have the comorbid disease of interest. Models were adjusted for age, sex, race, smoking status, education level and body mass index. Subjects were from the Atherosclerosis Risk in Communities Study during 1986-1989 and the Cardiovascular Health Study during 1989-1990. $\mathbf{~ : ~}$ with comorbid disease; $\square$ : without comorbid disease. GOLD 3/4: forced expiratory volume in one second (FEV 1 )/forced vital capacity (FVC) $<0.70$ and $\mathrm{FEV}_{1}<50 \%$ predicted; GOLD 2 $\mathrm{FEV}_{1} / \mathrm{FVC}<0.70$ and $\mathrm{FEV}_{1} \geqslant 50$ to $<80 \%$ pred; GOLD 1: FEV $1 / \mathrm{FVC}<0.70$ and FEV $1 \geqslant 80 \%$ pred; restricted (R): FEV $1 / F V C \geqslant 0.70$ and FVC $<80 \%$ pred; GOLD 0 : presence of respiratory symptoms in the absence of any lung function abnormality and no lung disease. 


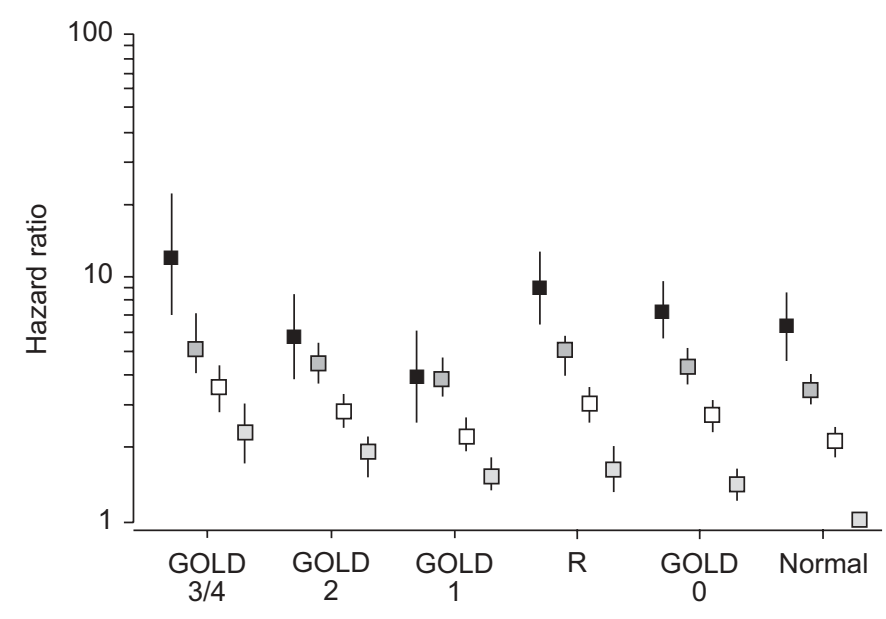

FIGURE 4. Results from Cox proportional hazard models (presented as hazard ratio with $95 \%$ confidence interval) that predict time to first hospitalisation within 5 yrs by modified Global Initiative for Obstructive Lung Disease (GOLD) category and the presence of none $(\square)$, one $(\square)$, two $(\square)$ or three $(\square)$ comorbid diseases (diabetes, hypertension or cardiovascular disease). The reference group (normal) was subjects with normal lung function for each comorbid disease. Models were adjusted for age, sex, race, smoking status, education level and body mass index. Subjects were from the Atherosclerosis Risk in Communities Study during 1986-1989 and the Cardiovascular Health Study during 1989-1990. $\mathbf{m}$ : with comorbid disease; $\square$ : without comorbid disease. GOLD 3/4: forced expiratory volume in one second (FEV1)/forced vital capacity (FVC) $<0.70$ and $\mathrm{FEV}_{1}<50 \%$ predicted; GOLD 2: FEV1/FVC $<0.70$ and FEV1 $\geqslant 50$ to $<80 \%$ pred; GOLD 1: $\mathrm{FEV}_{1 /}$ $\mathrm{FVC}<0.70$ and $\mathrm{FEV}_{1} \geqslant 80 \%$ pred; restricted $(\mathrm{R})$ : $\mathrm{FEV} 1 / \mathrm{FVC} \geqslant 0.70$ and $\mathrm{FVC}<80 \%$ pred; GOLD 0: presence of respiratory symptoms in the absence of any lung function abnormality and no lung disease.

BMI and altered respiratory compliance, weakness of the respiratory muscles, neuropathies or other undefined factors.

In addition, the analysis found an association between GOLD stage 2 COPD and higher and restriction on spirometry and the presence of hypertension. Hypertension is an early manifestation of cardiovascular disease so a possible explanation of the association is that the same factors explaining the link between respiratory and cardiovascular disease are important here.

The presence of multiple comorbid diseases was also found to be significantly increased among subjects with most classes of respiratory impairment (GOLD 0, GOLD 2 or higher, and restricted; table 4). This is an area of particular interest given the recent attention to the presence of a chronic systemic inflammatory syndrome that hypothesises the role of a chronic inflammatory process resulting in the development of multiple chronic diseases [35]. The present data support this concept and also provide data suggesting that additive comorbid conditions affect outcomes in COPD. These findings raise the possibility that interventions in early COPD may best target the inflammatory and systemic component of the disease, rather than the lung disease per se.

\section{Limitations}

The strengths of the current study include the two large cohorts of subjects, a reasonable length of follow-up and welldefined outcome events. However, the study subjects were not chosen to reflect a national sample so these results do not necessarily reflect what might be seen in the USA population. However, even though this is a large study, subgroups of interest could be small, e.g. only 14 subjects with GOLD stage 3 or 4 COPD had all three comorbid diseases present. Subjects were classified by COPD stage based on initial pre-bronchodilator spirometry, which may not have represented a true baseline for various reasons. In addition, the restricted category was included based on a decreased FVC alone rather than the gold standard, total lung capacity measurements.

\section{Conclusions}

In conclusion, a significant relationship was found between respiratory impairment and the presence of comorbid cardiovascular disease, diabetes mellitus and hypertension. It was also found that subjects with respiratory impairment were more likely to have at least two of these conditions and a significantly higher risk of death and hospitalisations, especially when comorbid disease is present. These findings suggest that the presence of respiratory impairment could provide a rationale to look for other comorbid disease and, conversely, that the presence of diabetes, hypertension or cardiovascular disease might be the basis for the evaluation of patients regarding respiratory impairment.

\section{ACKNOWLEDGEMENTS}

The authors would like to thank the staff and subjects in the Atherosclerosis Risk in Communities (ARIC) Study and the Cardiovascular Health Study (CHS) for their invalid contributions. The ARIC Study and CHS are conducted and supported by the National Heart Lung and Blood Institute (NHLBI) in collaboration with the ARIC and CHS Investigators. The present study was not prepared in collaboration with investigators of the ARIC or CHS and does not necessarily reflect the opinions or views of the ARIC, CHS or the NHLBI.

\section{REFERENCES}

1 Mannino DM, Homa DM, Akinbami LJ, Ford ES, Redd SC. Chronic obstructive pulmonary disease surveillanceUnited States, 1971-2000. MMWR Surveill Summ 2002; 51: $1-16$.

2 Chen JC, Mannino DM. Worldwide epidemiology of chronic obstructive pulmonary disease. Curr Opin Pulm Med 1999; 5: 93-99.

3 Celli BR, MacNee W, Augusti A, et al. Standards for the diagnosis and treatment of patients with COPD: a summary of the ATS/ERS position paper. Eur Respir J 2004; 23: 932-946.

4 Havranek EP, Masoudi FA, Westfall KA, Wolfe P, Ordin DL, Krumholz HM. Spectrum of heart failure in older patients: results from the National Heart Failure project. Am Heart J 2002; 143: 412-417.

5 Holguin F, Folch E, Redd SC, Mannino DM. Comorbidity and mortality in COPD-related hospitalizations in the United States, 1979 to 2001. Chest 2005; 128: 2005-2011.

6 Mannino DM, Doherty D, Aguayo SM, Petty TL, Redd SC. Low lung function and incident lung cancer in the United States: data from the first National Health and Nutrition Examination Survey follow-up. Arch Intern Med 2003; 163: 1475-1480. 
7 Di Marco F, Verga M, Reggente M, et al. Anxiety and depression in COPD patients: the roles of gender and disease severity. Respir Med 2006; 100: 1767-1774.

8 Sin DD, Man JP, Man SF. The risk of osteoporosis in Caucasian men and women with obstructive airways disease. Am J Med 2003; 114: 10-14.

9 Ernst P, Baltzan M, Deschenes J, Suissa S. Low-dose inhaled and nasal corticosteroid use and the risk of cataracts. Eur Respir J 2006; 27: 1168-1174.

10 Antonelli-Incalzi R, Fuso L, DeRosa M, et al. Co-morbidity contributes to predict mortality of patients with chronic obstructive pulmonary disease. Eur Respir J 1997; 10: 2794-2800.

11 Rana JS, Mittleman MA, Sheikh J, et al. Chronic obstructive pulmonary disease, asthma, and risk of type 2 diabetes in women. Diabetes Care 2004; 27: 2478-2484.

12 The Atherosclerosis Risk in Communities (ARIC) Study: design and objectives. The ARIC investigators. Am J Epidemiol 1989; 129: 687-702.

13 Fried LP, Borhani NO, Enright P, et al. The Cardiovascular Health Study: design and rationale. Ann Epidemiol 1991; 1: 263-276.

14 ATS statement-Snowbird workshop on standardization of spirometry. Am Rev Respir Dis 1979; 119: 831-838.

15 Hankinson JL, Odencrantz JR, Fedan KB. Spirometric reference values from a sample of the general U.S. population. Am J Respir Crit Care Med 1999; 159: 178-187.

16 Executive summary of the clinical guidelines on the identification, evaluation, and treatment of overweight and obesity in adults. Arch Intern Med 1998; 158: 1855-1867.

17 Global Strategy for the Diagnosis, Management and Prevention of COPD. Global Initiative for Chronic Obstructive Lung Disease (GOLD), 2007. www.goldcopd. com $/$ Guidelineitem.asp $11=2 \& 12=1 \&$ intId $=989$ Date last accessed: March 6, 2008.

18 Rabe KF, Hurd S, Anzueto A, et al. Global strategy for the diagnosis, management, and prevention of chronic obstructive pulmonary disease: GOLD executive summary. Am J Respir Crit Care Med 2007; 176: 532-555.

19 Mannino DM, Davis KJ. Lung function decline and outcomes in an elderly population. Thorax 2006; 61: 472-477.

20 Sin DD, Man SF. Chronic obstructive pulmonary disease: a novel risk factor for cardiovascular disease. Can J Physiol Pharmacol 2005; 83: 8-13.

21 Mancini GB, Etminan M, Zhang B, Levesque LE, Fitzgerald JM, Brophy JM. Reduction of morbidity and mortality by statins, angiotensin-converting enzyme inhibitors, and angiotensin receptor blockers in patients with chronic obstructive pulmonary disease. J Am Coll Cardiol 2006; 47: 2554-2560.
22 Curkendall SM, DeLuise C, Jones JK, et al. Cardiovascular disease in patients with chronic obstructive pulmonary disease, Saskatchewan Canada cardiovascular disease in COPD patients. Ann Epidemiol 2006; 16: 63-70.

23 Le Jemtel TH, Padeletti M, Jelic S. Diagnostic and therapeutic challenges in patients with coexistent chronic obstructive pulmonary disease and chronic heart failure. $J$ Am Coll Cardiol 2007; 49: 171-180.

24 Kiechl S, Werner P, Egger G, et al. Active and passive smoking, chronic infections, and the risk of carotid atherosclerosis: prospective results from the Bruneck Study. Stroke 2002; 33: 2170-2176.

25 Naunheim KS, Wood DE, Krasna MJ, et al. Predictors of operative mortality and cardiopulmonary morbidity in the National Emphysema Treatment Trial. J Thorac Cardiovasc Surg 2006; 131: 43-53.

26 Johnston AK, Mannino DM, Hagan GW, Davis KJ, Kiri VA. Relationship between lung function impairment and incidence or recurrence of cardiovascular events in a middle-aged cohort. Thorax 2008; 63: 599-605.

27 Arcavi L, Benowitz NL. Cigarette smoking and infection. Arch Intern Med 2004; 164: 2206-2216.

28 Gan WQ, Man SF, Sin DD. The interactions between cigarette smoking and reduced lung function on systemic inflammation. Chest 2005; 127: 558-564.

29 Kohler D, Fischer J, Raschke F, Schonhofer B. Usefulness of GOLD classification of COPD severity. Thorax 2003; 58: 825.

30 Irwin RS, Baumann MH, Bolser DC, et al. Diagnosis and management of cough executive summary: ACCP evidence-based clinical practice guidelines. Chest 2006; 129: Suppl. 1, 1S-23S.

31 de Marco R, Accordini S, Cerveri I, et al. An international survey of chronic obstructive pulmonary disease in young adults according to GOLD stages. Thorax 2004; 59: 120-125.

32 Ford ES, Mannino DM. Prospective association between lung function and the incidence of diabetes: findings from the National Health and Nutrition Examination Survey Epidemiologic Follow-up Study. Diabetes Care 2004; 27: 2966-2970.

33 Bolton CE, Evans M, Ionescu AA, et al. Insulin resistance and inflammation: a further systemic complication of COPD. COPD 2007; 4: 121-126.

34 Engstrom G, Hedblad B, Nilsson P, Wollmer P, Berglund G, Janzon L. Lung function, insulin resistance and incidence of cardiovascular disease: a longitudinal cohort study. $J$ Intern Med 2003; 253: 574-581.

35 Fabbri LM, Rabe KF. From COPD to chronic systemic inflammatory syndrome? Lancet 2007; 370: 797-799. 